\title{
Kajian Updating Data Sampah Lokasi Kabupaten Lampung Selatan
}

\author{
Mirnanda Cambodia $^{(1)^{*}}$, Elza Novilyansa ${ }^{(2)}$, Yunita Mauliana ${ }^{(3)}$ \\ ${ }^{(1)}$ Universitas Sang Bumi Ruwa Jurai, ${ }^{(1)}$ Universitas Sang Bumi Ruwa Jurai, ${ }^{(1)}$ Universitas Sang Bumi Ruwa Jurai \\ email korespondensi: mirnanda.cambodia.mc@gmail.com ${ }^{{ }^{*}}$
}

\begin{abstract}
Abstrak.
Kota-kota di Indonesia sebagian besar dihadapkan dengan permasalahan sampah dan pengelolaannya. Pengelolaan sampah yang dilakukan sampai saat ini belum sesuai dengan metode dan teknik pengelolaan sampah yang berwawasan lingkungan. Kabupaten Lampung Selatan merupakan salah satu Kabupaten di Provinsi Lampung. Sebagai kabupaten yang berkembang cukup pesat, terutama dalam hal fisik dan jumlah penduduknya, hal itu berimbas pada peningkatan volume timbulan sampah yang dihasilkan. Sampai saat ini tingkat layanan pengangkutan sampah belum optimal khususnya untuk kawasan perkotaan Kalianda. Untuk meningkatkan situasi dan kondisi pengelolaan persampahan, sangat diperlukan kajian tersendiri secara cermat agar proses pengelolaan sampah dapat ditingkatkan sehingga menjadi lebih baik dan terpadu dalam menyikapi volume timbulan sampah.
\end{abstract}

Kata Kunci: Analisis Updating, Sampah, Timbulan Sampah, Pengelolaan Sampah

\begin{abstract}
.
Most of the cities in Indonesia are faced with the problem of waste and its management. Waste management that has been carried out so far has not been in accordance with environmentally sound waste management methods and techniques. South Lampung Regency is one of the regencies in Lampung Province. As a district that is developing quite rapidly, especially in terms of physicality and population, this has resulted in an increase in the volume of waste generated. Until now, the level of waste transportation services has not been optimal, especially for the Kalianda urban area. In order to improve the situation and condition of solid waste management, careful separate studies are needed so that the waste management process can be improved so that it becomes better and more integrated in addressing the volume of waste generation.
\end{abstract}

Keywords: updating analysis, Waste, Waste Generation, Waste Management

\section{PENDAHULUAN}

Sampah selalu menjadi persoalan utama khususnya bagi wilayah perkotaan dikarenakan dampaknya bagi kesehatan dan kenyamanan manusia. Volumenya dan jenisnya kian bertambah setiap tahunnya berbanding lurus dengan pertambahan jumlah penduduk, tuntutan gaya hidup dan kebutuhan serta aktivitas manusia yang kian beragam setiap tahunnya.

Peningkatan volume timbulan sampah juga akan mendorong bertambahnya tuntutan akan pelayanan yang efektif, efisien dan berkelanjutan demi terwujudnya lingkungan yang bersih, sehat dan memiliki nilai keindahan suatu kota. Pengelolaan sampah sangat dibutuhkan dalam perkembangan suatu kota, dimana jaringan persampahan merupakan salah satu aspek yang berpengaruh terhadap citra suatu kota. Pengelolaan sampah yang baik dan terarah akan menciptakan keindahan dan kebersihan pada suatu kota ataupun lingkungan permukiman. Oleh sebab itu, pengelolaan sampah yang baik harus segera diadakan sebagai bentuk dari pengendalian dan penanggulangan atas segala dampak negatif yang mungkin ditimbulkan dari keberadaan sampah yang tidak tertangani dengan baik (Dinas kebersihan dan Pertamanan, 2014).

Kabupaten Lampung Selatan merupakan salah satu Kabupaten di Provinsi Lampung. Sebagai kabupaten yang berkembang cukup pesat, terutama dalam hal fisik dan jumlah penduduknya, hal itu berimbas pada peningkatan volume timbulan sampah yang 
dihasilkan. Sampai saat ini tingkat layanan pengangkutan sampah belum optimal khususnya untuk kawasan perkotaan Kalianda. Untuk meningkatkan situasi dan kondisi pengelolaan persampahan, sangat diperlukan kajian tersendiri secara cermat agar proses pengelolaan sampah dapat ditingkatkan sehingga menjadi lebih baik dan terpadu dalam menyikapi volume timbulan sampah.

\section{Sampah}

Definisi sampah menurut UU-18/2008 tentang Pengelolaan Sampah adalah sisa kegiatan sehari-hari manusia dan/atau proses alam yang berbentuk padat. Sampah spesifik adalah sampah yang karena sifat, konsentrasi, dan/atau volumenya memerlukan pengelolaan khusus. Sampah yang dikelola berdasarkan Undang-Undang terdiri atas sampah rumah tangga, Sampah sejenis sampah rumah tangga dan Sampah spesifik (Indonesia, 2008).

\section{Timbulan Sampah}

Timbulan sampah merupakan banyaknya sampah yang timbul dari masyarakat dalam satuan volume maupun per kapita perhari atau perluas bangunan atau perpanjang jalan. Besarnya timbulan sampah berbanding lurus dengan bertambahnya jumlah penduduk di suatu wilayah (Tampuyak et al., 2016).

Beberapa faktor penting dalam menghitung laju timbulan sampah, antara lain perkembangan jumlah penduduk, survey pengambilan contoh sampah di sumber sampah dan penentuan densitas sampah yang diukur dalam satuan kilogram dibandingkan dengan volume sampah yang diukur tersebut $\left(\mathrm{kg} / \mathrm{m}^{3}\right)$. Metode proyeksi perhitungan jumlah penduduk yang dapat dilakukan antara lain metoda least square, geometric dan eksponensial (Aritmatik) (Badan Standarisasi Nasional, 2002).
Tabel 1. Timbulan Sampah berdasarkan Komponen Sumber Sampah

\begin{tabular}{|c|c|c|c|c|}
\hline So & $\begin{array}{l}\text { Kosepeasa Sember } \\
\text { Saruphl }\end{array}$ & Satean & $\begin{array}{l}\text { Volume } \\
\text { Alwer! }\end{array}$ & $\begin{array}{l}\text { Berns } \\
\left(\mathbf{K}_{\mathrm{s}}\right)\end{array}$ \\
\hline$t$ & Rumud Ptemines & per erstan & $123-2.50$ & $0.350-0.40 t$ \\
\hline 2 & Rami Seni Permone & ye erhan & $200 \div 221$ & $0.300=0.350$ \\
\hline 3 & Remmil ame permant & $p=\operatorname{arn} 2 a n$ & $1.75-2.00$ & $0.250-0.350$ \\
\hline 4 & Eavar & per gequmilati & $0.50-0,75$ & $0,025-0.100$ \\
\hline 5 & Folv'Kuike & pe pertugakm & $230-500$ & $0.150-0.550$ \\
\hline 6 & Sebwlil & per antithei & $0.10-0.15$ & $0,010-0.020$ \\
\hline 7 & Jabt atsvi selocuder & per sentritaxi & $0.10-0.15$ & $0.000-0.100$ \\
\hline 3 & 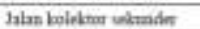 & per artnilusi & $010-015$ & $0010-0030$ \\
\hline 9 & Slat lekal & per arimihni & $005-01$ & $0.005-0.015$ \\
\hline 10 & P2EI & per mertrotan & $0.20-0.00$ & $0.1-0.3$ \\
\hline
\end{tabular}

Tabel 2. Timbulan Sampah berdasarkan Klasifikasi

\begin{tabular}{|c|c|c|c|}
\hline \multicolumn{4}{|c|}{ kota } \\
\hline $\mathrm{Na}$ & Kasifikasi Kots & $\begin{array}{l}\text { Volumi } \\
\text { (LOrasog Hart) }\end{array}$ & $\begin{array}{c}\text { Betat } \\
\text { (KeOrang/Hard) }\end{array}$ \\
\hline 1 & $\begin{array}{c}\text { Kota Besar } \\
(500000-1000000 \text { yma })\end{array}$ & $2,75-3,25$ & $0,70-0,80$ \\
\hline 2 & $\begin{array}{c}\text { Kota Sedang } \\
(100.000-500.000 \text { jwa) }\end{array}$ & $2,75-3,25$ & $0,70=0,80$ \\
\hline 3 & $\begin{array}{c}\text { Kota Kecil } \\
(20.000-100.000 \text { jwa })\end{array}$ & $2,50-2,75$ & $0.625-0.70$ \\
\hline
\end{tabular}

\section{Komposisi Sampah}

Pengelompokan sampah yang sering dilakukan adalah berdasarkan komposisinya, misalnya dinyatakan sebagai \% berat (biasanya berat basah) atau \% volume (basah) dari kertas, kayu, kulit, karet, plastik, logam, kaca, kain, makanan, dan lain-lain. Berikut tabel yang menggambarkan tipikal komposisi sampah pemukiman di kota di negara maju dan contoh komposisi sampah kota di beberapa tempat di dunia. Komposisi dan sifat-sifat sampah menggambarkan keanekaragaman aktivitas manusia (Dewilda \& Julianto, 2019).

Tabel 3. Komposisi Sampah Domestik

\begin{tabular}{|c|c|c|}
\hline Kategori sampah & \% Berat & \% Volume \\
\hline Kectas dat bahan-dahan kertas & $32: 98$ & 6261 \\
\hline Kava jeoduk thri kaye & 0,34 & 0,15 \\
\hline Mastak, kulit, dan pmatuk kares & 6,84 & 306 \\
\hline Kain dan produk fekstil & 6,36 & 5,1 \\
\hline Cietios & 16,06 & 5.11 \\
\hline Lexam & 10,74 & 9.12 \\
\hline Buhan batus pasir & 0,26 & $0,0,07$ \\
\hline Sammih ocganic & 26,28 & 8,58 \\
\hline
\end{tabular}

Dengan mengetahui komposisi sampah dapat ditentukan cara pengolahan yang tepat dan yang paling efisien sehingga dapat diterapkan proses pengolahannya. Tipikal komposisi sampah didasarkan atas tingkat pendapatan digambarkan pada tabel di bawah 
ini. Tambah sederhana pola hidup masyarakatnya, tambah banyak komponen sampah organik (sisa makanan, dsb).

\section{Daur Ulang Sampah}

Terminologi daur-ulang di Indonesia sudah cukup lama digunakan, namun selama ini pengertiannya bukan hanya identik dengan recycle, tapi digunakan juga untuk menjelaskan aktivitas lain, seperti reuse dsb. Jadi terminologi 'daur-ulang' di Indonesia biasanya digunakan untuk seluruh upaya pemanfaatan kembali. Sebelum terminologi 3R menjadi acuan umum dalam penanganan sampah dikenal beragam terminologi yang menggunakan "R", seperti recovery, reduce, reuse, recycle, refurbishment, repair, sampai kepada rethinking dan masih banyak lagi (Putra, 2018).

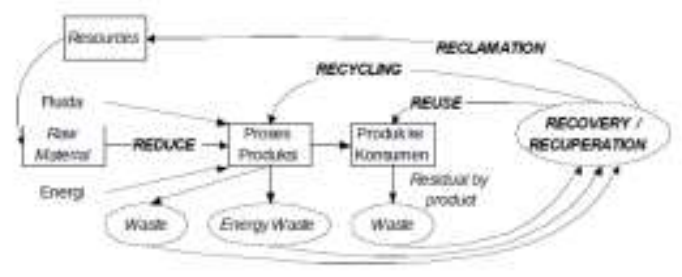

Gambar 1. Konsep Daur-Ulang Sampah

\section{METODE PELAKSANAAN}

Tahapan yang dilakukan di dalam penelitian ini yaitu sebagai berikut :

a. Tahap Persiapan

Tahap ini akan dilakukan kegiatan persiapan mulai dari kegiatan mobilisasi personil, studi literature, penyusunan target pekerjaan, pembagian tugas dan tanggung jawab setiap personil dan mempersiapkan material, bahan dan alat yang dibutuhkan dalam pekerjaan ini.

b. Tahap Survey dan Pengumpulan Data

Pengumpulan data dilakukan untuk mendapatkan data-data sekunder dan data primer. Data primer didadapatkan dengan cara terjun langsung ke lapangan. Data sekunder diperoleh dari instansi-intansi sebagai datadata pelengkap dalam penyusunan laporan dan sebagai data acuan ketika terjun langsung ke lapangan. Data yang diperoleh dari hasil survey yaitu data infrastruktur bidang persampahan yang berupa sarana pengumpul sampah perkotaan, sarana pengangkutan sampah perkotaan, sarana pengolahan sampah perkotaan serta tempat pembuangan akhir sampah.

\section{HASIL DAN PEMBAHASAN}

\section{Sarana Pengumpul Sampah Perkotaan}

Sarana pengumpul sampah di wilayah Kabupaten Lampung Selatan yaitu berupa Tempat Pembuangan Sementara (TPS) serta Bank Sampah. TPS yang ada berupa bangunan permanen dinding bata dan kontainer dengan berbagai kapasitas yang ditempakan pada lokasi strategis sehingga memudahkan warga perkotaan untuk membuang sampahnya. Berikut data sebaran TPS dan Bank Sampah yang ada di Kabupaten Lampung Selatan:

Tabel 4. Sebaran Lokasi TPS di Kabupaten Lampung Selatan

\begin{tabular}{|c|l|l|c|}
\hline N0 & \multicolumn{1}{|c|}{ URAIAN } & \multicolumn{1}{|c|}{ LOKASI } & KET \\
\hline 1 & TPS PT BSL & DESA BAKAUHENI & AKTIF \\
\hline 2 & TPS PASAR PASURUAN & DESA PASURUAN KEC PENENGAHAN & AKTIF \\
\hline 3 & TPS PASAR PEMATANG PASIR & DESA PEMATANG PASIR KEC KETAPANG & AKTIF \\
\hline 4 & TPS PASAR PALAS JAYA & DESA PALAS JAYA KEC. PALAS & AKTIF \\
\hline 5 & TPS PASAR INPRES & KEL KALIANDA & AKTIF \\
\hline 6 & TPS PASAR SIDOMULYO & DESA SIDOREJO KEC SIDOMULYO & AKTIF \\
\hline 7 & TPS PASAR RAWASELAPAN & DESA RAWA SELAPN KECCANDIPUR0 & AKTIF \\
\hline 8 & TPS PASAR BERINGIN KENCANA & DESA BERINGIN KENCANA KEC CANDIPURO & AKTIF \\
\hline 9 & TPS PASAR KATIBUNG & DESA TANJUNG AGUNG KEC KATBUNG & AKTIF \\
\hline 10 & TPS PASAR JATI MULYO & DESA JATIMULYO KEC JATIAGUNG & AKTIF \\
\hline 11 & TPS PASAR MARGODADI & DESA MARGODADI KEC JATIAGUNG & AKTIF \\
\hline 12 & TPS PASAR TANJUNGBINTANG & DESA JATIBARU KEC TANJUNGBINTANG & AKTIF \\
\hline 13 & TPS PASAR NATAR & DESA NATAR KECAMATAN NATAR & AKTIF \\
\hline 14 & TPS PASAR BRANTI RAYA & DESA BRANTI KEC. NATAR & AKTIF \\
\hline
\end{tabular}

Tabel 5. Sebaran Lokasi Bank Sampah di Kab. Lampung Selatan

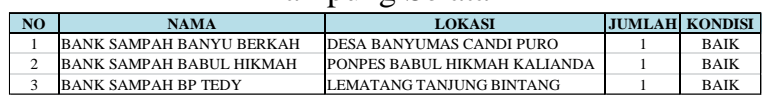

Sumber : Dinas Lingkungan Hidup Kab. Lamsel, 2020

\section{Sarana Pengangkutan Sampah Perkotaan}

Sarana pengangkutan sampah dari TPS menuju TPA yaitu dengan menggunakan 13 
unit armada truk arm roll kapasitas 6 ton dan pengangkutan sampah dari sumber sampah ke TPS di angkut oleh 4 unit motor roda tiga kapasitas 1,25 ton, 1 truk tangki siram, 1 unit Buldozer/Exavator. Kegiatan pengangkutan sampah dari TPS ke TPA adalah sebanyak 2 kali pengangkutan dalam satu hari.

\section{Sarana Pengolahan Sampah Perkotaan}

Berdasarkan data yang diperoleh dari Dinas Lingkungan Hidup Kabupaten Lampung
Selatan, jumlah fasilitas TPS3R yang ada di Kabupaten Lampung Selatan adalah 6 unit TPS3R. Namun sampai saat ini TPS3R tersebut tidak beroperasi secara maksimal sehingga tidak terjadi pengolahan sampah di lokasi tersebut. Hal ini disebabkan karena kurangnya pemahaman masyarakat terkait pengolahan sampah dan juga akibat dari kurangnya biaya operasional. Berikut titik TPS3R di Kec. Kalianda Kab. Lampung Selatan:

Tabel 6. Titik TPS3R di Kec. Kalianda Kab.Lampung Selatan

\begin{tabular}{cllcc}
\hline No & \multicolumn{1}{c}{ Nama } & \multicolumn{1}{c}{ Lokasi } & Jumlah & Kondisi \\
\hline 1 & TPS 3 R RAGOM & KOMPLEK RAGOM 2 & 1 & BAIK \\
2 & TPS 3 R DESA PISANG & DESA PISANG & 1 & BAIK \\
3 & TPS 3 R BERINGIN & DESA BERINGIN KENCANA & 1 & BAIK \\
\hline \multicolumn{2}{l}{ Sumber : Dinas Lingkungan Hidup Kab. Lamsel, 2020 }
\end{tabular}

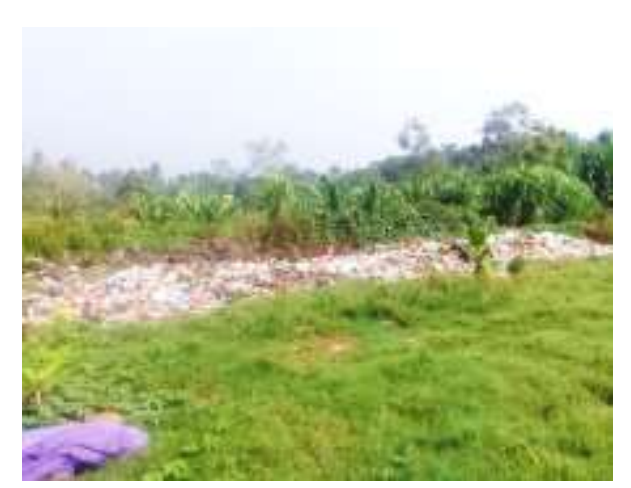

Gambar 2. Kondisi TPS3R di Kab. Lam-Sel

Sarana pengumpul maupun pengolahan sampah saat ini belum beroperasi secara maksimal dikarenakan kurangnya minat dan kesadaran masyarakat dalam hal mengolah sampah juga kaitannya dengan biaya operasional yang tidak tersedia untuk melaksanakan pengolahan sampah di lokasi tersebut.

Pengurangan sampah juga dapat di tempuh dengan cara:

- Pembatasan Timbulan Sampah, Salah satu upaya dalam mengurangi sampah khususnya sampah di wilayah perkotaan yaitu dengan cara mambatasi timbulan sampah (reduce) dimulai dari sumbernya. Seperti yang kita ketahui bahwa sumber sampah selain berasal dari kegiatan rumah tangga juga bersalal dari kegiatan perkantoran, pasar tradisional, pertokoan, sekolah, rumah sakit, rumah ibadah, restoran atau rumah makan dan sebagainya. Untuk itu pemerintah harus memulai kegiatan pengurangan sampah di hulu agar lebih mudah menangani sampah bagian hilirnya.

- Jumlah Sampah Termanfaatkan, Kegiatan lain yang dapat dilakukan untuk mengurangi sampah perkotaan yaitu dengan cara meningkatkan jumlah sampah yang termanfaatkan kembali (reuse). Jenis sampah yang bisa dimanfaatkan kembali yaitu sampah anorganik yang biasanya dikumpulkan pada Unit Bank Sampah atau pengepul sampah yang berada disekitar area perkotaan.

- Jumlah Sampah yang di Daur Ulang, Kegiatan mendaur ulang sampah juga akan sangat berdampak dalam upaya mengurangi timbulan sampah perkotaan. Kegiatan ini dapat dilakukan melalui Bank Sampah Unit maupun induk, TPS3R yang dikelola oleh Kelompok Swadaya Masyarakat (KSM) dan juga Pos Daur 
Ulang (PDU) yang juga dikelola oleh masyarakat sekitar.

\section{Tempat Pembuangan Akhir Sampah}

Kabupaten Lampung Selatan mempunyai 5 unit sarana Tempat Pemrosesan Akhir (TPA) sampah. Namun hanya 2 TPA yang beroperasi yaitu TPA Lubuk Kamal dan TPA Tanjung Sari. Sistem pengoperasian TPA sampah dipengaruhi oleh beberapa faktor yaitu sistem pengoperasian TPA, Sistem Pengolahan Lindi, dan sistem penanganan gas metan yang dihasilkan akibat pembuangan sampah di TPA. Sejauh ini TPA yang beroperasi di Kota Kalianda yaitu TPA Lubuk Kamal yang dibangun dan beroperasi dengan sistem control landfill. Untuk kualitas effluent air lindi yang dihasilkan dari TPA tersebut belum pernah dilakukan pengecekan secara berkala sehingga dapat disimpulkan bahwa kualitas air lindinya belum memenuhi standar baku mutu air limbah yang berlaku. Kemudian untuk sistem penanganan gas metan yang dihasilkan TPA Lubuk Kamal belum terdapat penanganan secara khusus sehingga gas metan yang ada masih terlepas bebas ke udara yang sewaktuwaktu dapat menyebabkan kebakaran.
Untuk mencapai target tersebut dibutuhkan beberapa strategi yaitu:

- Melakukan pengecekan effluent air lindi di TPA secara berkala untuk memastikan bahwa air lindi tersebut berstatus aman dan bisa dilepas ke badan air terdekat.

- Melakukan penanganan terhadap gas metan yang dihasilkan dari TPA Lubuk Kamal agar gas tersebut dapat dimanfaaatkan masyarakat sekitar.

- Penanganan sampah menjadi energi terbarukan misalnya dengan membuat briket sampah yang dapat diproses menjadi listrik agar dapat dimanfaatkan terutama oleh masyarakat yang berada di area TPA.

Dengan jumlah total penduduk di Kabupaten Lampung Selatan adalah sebesar 1.064,2 ribu jiwa (BPS, 2020), maka jumlah timbulan sampah perorang di asumsikan sebesar $0,70-0,80 \mathrm{~kg} /$ orang/hari sehingga akan menghasilkan timbulan sampah sebesar 271,90 ton/tahun. Berikut ini adalah besar timbulan sampah perkotaan di Kabupaten Lampung Selatan:

Tabel 7. Jumlah Timbulan Sampah Perkotaan di Kabupaten Lampung Selatan

$\begin{array}{ccccc} & \text { Jumlah Penduduk } & \begin{array}{c}\text { Timbulan } \\ \text { Sampah }\end{array} & \begin{array}{c}\text { Proyeksi Jumlah } \\ \text { Ponduduk (Ribu) }\end{array} & \begin{array}{c}\text { Proyeksi Timbulan } \\ \text { Sampah }(\text { Kg) }\end{array}\end{array}$

\begin{tabular}{|c|c|c|c|c|c|c|c|c|}
\hline & & 2019 & 2020 & $(\mathbf{K g})$ & 2021 & 2031 & 2021 & 2031 \\
\hline 1 & Natar & 187.42 & 191.80 & $49,004.90$ & 235.62 & 279.44 & $60,200.91$ & $71,396.92$ \\
\hline 2 & Jati Agung & 115.69 & 128.60 & $32,857.30$ & 257.73 & 386.86 & $65,850.02$ & $98,842.73$ \\
\hline 3 & $\begin{array}{l}\text { Tanjung } \\
\text { Bintang }\end{array}$ & 79.18 & 82.20 & $21,002.10$ & 112.40 & 142.60 & $28,718.20$ & $36,434.30$ \\
\hline 4 & Tanjung Sari & 31.52 & 31.80 & $8,124.90$ & 34.62 & 37.44 & $8,845.41$ & $9,565.92$ \\
\hline 5 & Katibung & 72.48 & 72.60 & $18,549.30$ & 73.79 & 74.98 & $18,853.35$ & $19,157.39$ \\
\hline 6 & $\begin{array}{l}\text { Merbau } \\
\text { Mataram }\end{array}$ & 54.31 & 56.50 & $14,435.75$ & 78.36 & 100.22 & $20,020.98$ & $25,606.21$ \\
\hline 7 & Way Sulan & 24.65 & 24.30 & $6,208.65$ & 20.85 & 17.40 & $5,327.18$ & $4,445.70$ \\
\hline 8 & Sidomulyo & 65.68 & 65.30 & $16,684.15$ & 61.54 & 57.78 & $15,723.47$ & $14,762.79$ \\
\hline 9 & Candipuro & 58.18 & 57.60 & $14,716.80$ & 51.84 & 46.08 & $13,245.12$ & $11,773.44$ \\
\hline 10 & Way Panji & 18.23 & 18.10 & $4,624.55$ & 16.78 & 15.46 & $4,287.29$ & $3,950.03$ \\
\hline 11 & Kalianda & 95.07 & 94.10 & $24,042.55$ & 84.39 & 74.68 & $21,561.65$ & $19,080.74$ \\
\hline 12 & Rajabasa & 25.23 & 24.80 & $6,336.40$ & 20.54 & 16.28 & $5,247.97$ & $4,159.54$ \\
\hline
\end{tabular}




\begin{tabular}{llccccccc} 
No & Kecamatan & $\begin{array}{c}\text { Jumlah Penduduk } \\
\text { (ribu) }\end{array}$ & $\begin{array}{c}\text { Timbulan } \\
\text { Sampah } \\
\text { per Tahun }\end{array}$ & $\begin{array}{c}\text { Proyeksi Jumlah } \\
\text { Penduduk (Ribu) }\end{array}$ & $\begin{array}{c}\text { Proyeksi Timbulan } \\
\text { Sampah (Kg) }\end{array}$ \\
& & & & & & & & \\
& & $\mathbf{2 0 1 9}$ & $\mathbf{2 0 2 0}$ & $(\mathbf{K g})$ & $\mathbf{2 0 2 1}$ & $\mathbf{2 0 3 1}$ & $\mathbf{2 0 2 1}$ & $\mathbf{2 0 3 1}$ \\
\hline 13 & Palas & 61.46 & 60.90 & $15,559.95$ & 55.35 & 49.80 & $14,141.93$ & $12,723.90$ \\
14 & Sragi & 36.22 & 35.70 & $9,121.35$ & 30.49 & 25.28 & $7,790.20$ & $6,459.04$ \\
15 & Penengahan & 42.42 & 42.30 & $10,807.65$ & 41.14 & 39.98 & $10,511.27$ & $10,214.89$ \\
16 & Ketapang & 53.49 & 53.10 & $13,567.05$ & 49.16 & 45.22 & $12,560.38$ & $11,553.71$ \\
17 & Bakauheni & 24.45 & 24.50 & $6,259.75$ & 24.98 & 25.46 & $6,382.39$ & $6,505.03$ \\
& Jumlah/Total & $\mathbf{1 , 0 4 5 . 6 6}$ & $\mathbf{1 , 0 6 4 . 2 0}$ & $\mathbf{2 7 1 , 9 0 3 . 1 0}$ & $\mathbf{1 , 2 4 9 . 5 8}$ & $\mathbf{1 , 4 3 4 . 9 6}$ & $\mathbf{3 1 9 , 2 6 7 . 6 9}$ & $\mathbf{3 6 6 , 6 3 2 . 2 8}$ \\
\hline
\end{tabular}

\section{KESIMPULAN DAN SARAN}

Dari hasil analisis dapat disimpulkan bahwa fasilitas pengurangan sampah yang tersedia di Kabupaten Lampung Selatan berupa 14 TPS semuanya aktif, 6 TPS3R sebagian dalam kondisi baik dan selebihnya rusak, 3 Bank Sampah semuanya dalam kondisi baik. Fasilitas Pengangkatan Sampah yang tersedia di Kabupaten Lampung Selatan yaitu berupa 13 unit armada truk arm roll kapasitas 6 ton dan pengangkatan sampah dari sumber sampah ke TPS di angkut oleh 4 unit motor roda tiga kapasitas 1,25 ton, 1 truk tangki siram, 1 unit Buldozer/Exavator. Kegiatan pengangkutan sampah dari TPS ke TPA adalah sebanyak 2 kali pengangkutan dalam satu hari. Sampai dengan bulan Juni 2020, data volume sampat yang terangkut ke TPA Lubuk Kamal Kecamatan Kalianda adalah sebesar 6.037,52 ton, sedangkan proyeksi timbulan sampah sampai dengan Juni 2021 adalah $159.633,85$ ton, sehingga baru $3,78 \%$ sampah yang terangkut ke TPA.

Dari hasil penelitian di atas pula, dapat ditentukan saran yaitu Kajian pengelolaan persampahan seharusnya dititikberatkan pada teknik inovasi pengelolaan persampahan, kajian kelayakan, dan pelibatan pihak ketiga. Dari kajian tersebut diharapkan dapat menjadi pedoman sebagai acuan dalam pembangunan pengelolaan persampahan di Kabupaten Lampung Selatan saat ini serta menjalankan amanat Undang-Undang RI Tahun 2008 tentang Pengelolaan Sampah dan Rencana Tata Ruang Wilayah Kabupaten Lampung Selatan tahun $2018-2038$

\section{DAFTAR PUSTAKA}

Badan Standarisasi Nasional. (2002). Tata Cara Teknik Operasional Pengelolaan Sampah Perkotaan. ICS 27.180, 31.

Dewilda, Y., \& Julianto, J. (2019). Kajian Timbulan, Komposisi, dan Potensi Daur Ulang Sampah Sebagai Dasar Perencanaan Pengelolaan Sampah Kawasan Kampus Universitas Putra Indonesia (UPI). Seminar Nasional Pembangunan Wilayah Dan Kota Berkelanjutan, 1(1), 142-151. https://doi.org/10.25105/pwkb.v1i1.52 70

Dinas kebersihan dan Pertamanan. (2014). Perencanaan Teknis Manajemen Persampahan di Kota Bukittinggi.

Indonesia, P. R. (2008). Undang-Undang Republik Indonesia No. 18 Tahun 2008. 46.

Putra, D. D. K. G. D. (2018). Analisis Karakteristik Sampah di Kota Denpasar, Kabupaten Badung dan Tempat Pemrosesan Akhir (Tpa) Suwung Bali.

Tampuyak, S., Anwar, C., \& Sangadji, M. N. (2016). Analisis Proyeksi Pertumbuhan 
Penduduk dan Kebutuhan Fasilitas

Persampahan di Kota Palu 2015-2025.

E Jurnal Katalogis, 4(4), 94-104. 